\title{
Hyoscine N-Butylbromide for Preventing Propofol Injection Pain: A Randomized, Placebo-Controlled and Double-Blind Study
}

\author{
Mehmet Sargın Mehmet Selçuk Uluer Eyüp Aydoğan \\ Department of Anesthesiology and Reanimation, Konya Training and Research Hospital, Konya, Turkey
}

\section{Significance of the Study}

- In this study, the effect of hyoscine N-butylbromide (HnBB) pretreatment of pain during propofol injection was investigated. Pretreatment with $20 \mathrm{mg} \mathrm{HnBB}$ significantly reduced propofol injection compared to placebo. It is probable that pretreatment with $\mathrm{HnBB}$ could relieve pain in a select group of patients.

\section{Keywords}

Hyoscine N-butylbromide · Propofol · Injection pain

\begin{abstract}
Objective: In this study, the aim was to investigate the effect of hyoscine $\mathrm{N}$-butylbromide ( $\mathrm{HnBB}$ ) pretreatment on pain during propofol injection. Subjects and Methods: In this prospective, randomized, placebo-controlled and doubleblind trial, 60 patients scheduled to undergo routine outpatient surgery under general anesthesia were randomly allocated to 2 groups, the $\mathrm{HnBB}(n=30)$ and sodium chloride ( $n=30$ ) groups. Twenty seconds after the injection of $20 \mathrm{mg}$ $\mathrm{HnBB}$ or $0.9 \%$ sodium chloride, a $50-\mathrm{mg}$ dose of propofol was injected in 2-3 s. Ten seconds later, the pain intensity was assessed using a 4-point scale: no pain (0), mild (1), moderate (2), and severe (3) pain. The Student $t$ test was used for the analysis of parametric data and the Pearson $X^{2}$ test for categorical data. Results: The occurrence of pain in the $\mathrm{HnBB}$
\end{abstract}

\begin{tabular}{ll}
\hline KARGER & $\begin{array}{l}\text { ( ) 2018 The Author(s) } \\
\text { Published by S. Karger AG, Basel Openger }\end{array}$ \\
E-Mail karger@karger.com & $\begin{array}{l}\text { This is an Open Access article licensed under the Creative Commons } \\
\text { Attribution-NonCommercial-4.0 International License (CC BY-NC) } \\
\text { (http://www.karger.com/Services/OpenAccessLicense), applicable to } \\
\text { the online version of the article only. Usage and distribution for } \\
\text { commercial purposes requires written permission. }\end{array}$
\end{tabular}

group (43.3\%) was significantly lower than the control group $(73.3 \%)(p<0.018)$. Of the 30 patients in each group, 10 in the control group and 3 in the HnBB group experienced severe pain ( $p=0.001)$. Conclusions: Pretreatment with $20 \mathrm{mg}$ $\mathrm{HnBB}$ significantly reduced propofol injection pain compared to placebo.

(c) 2018 The Author(s)
Published by S. Karger AG, Basel

\section{Introduction}

Propofol is widely used for the induction and maintenance of general anesthesia and also sedation, due to its rapid activation, short duration of action, and easy titration [1]. However, the pain induced by propofol injection is a common problem, and this leads to discomfort, which can lead to discontent with the anesthesia; the incidence of this pain varies from 28 to $90 \%$ in adults $[1,2]$. Several 


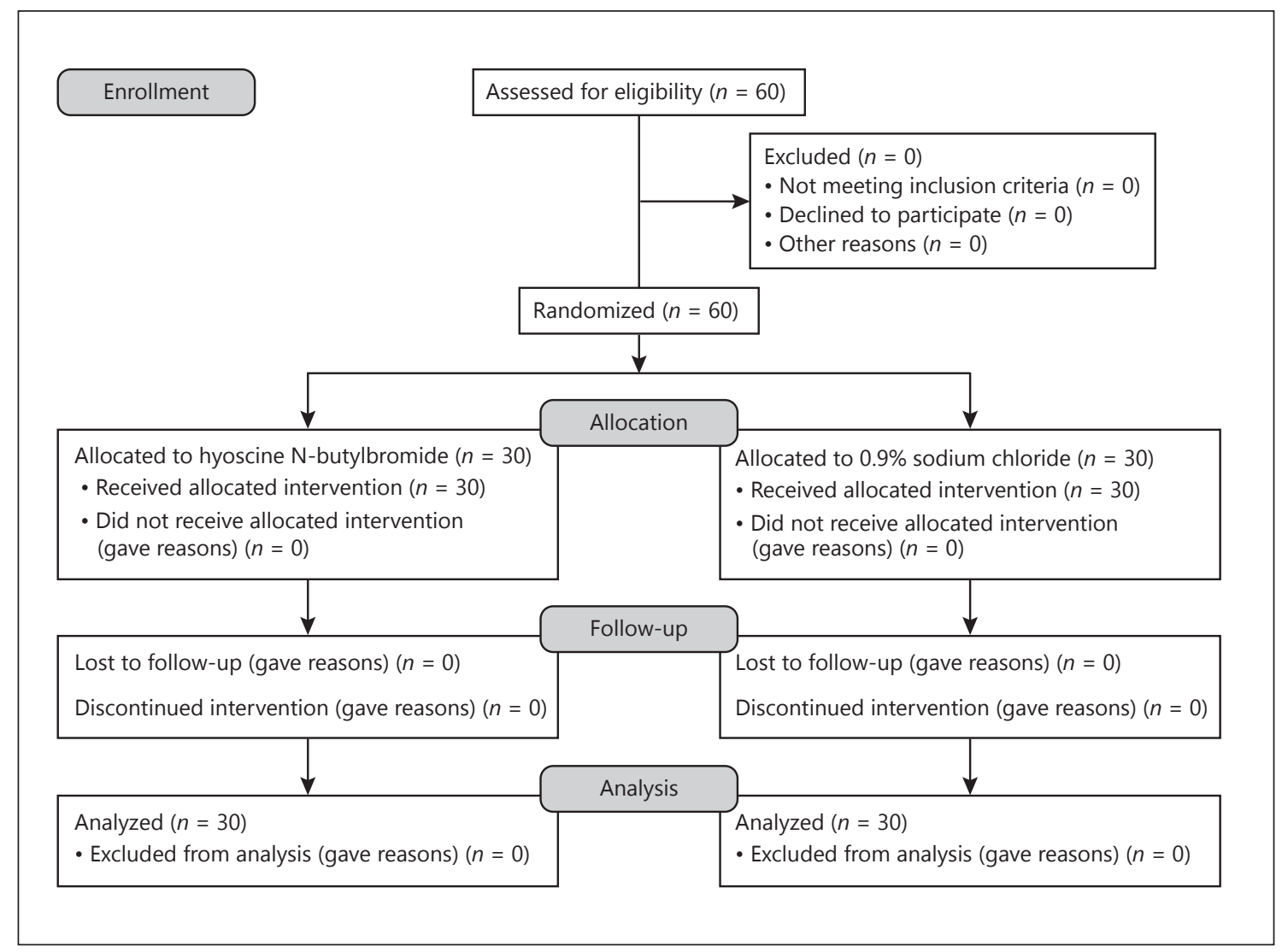

Fig. 1. Study and data analysis flowchart.

methods have been used to reduce propofol injection pain, including using larger veins, cooling, warming, or diluting the propofol solution, and preinjecting lidocaine, benzodiazepines, metoclopramide, ondansetrone, granisetron, magnesium, opioids, flurbiprofen, ephedrine, ketamine, or thiopental with or without a tourniquet; all have been investigated with variable results $[1,3-5]$. Among them, lidocaine pretreatment is the most popular method for reducing propofol injection pain [6]. However, despite the use of this treatment, propofol injection pain has not been abolished completely, and the failure rate is $32-48 \%[6,7]$. Therefore, combination therapy had been suggested for the prevention of propofol injection pain [8].

Hyoscine N-butylbromide ( $\mathrm{HnBB}$ ) is a quaternary ammonium derivative that exerts peripheral anticholinergic effects by inhibiting muscarinic acetylcholine (ACh) receptors in the smooth-muscle cells of the visceral hollow organs [9]. Because it does not cross the blood-brain barrier, this anticholinergic action is limited to the peripheral tissues, and it exerts its effect by blocking the transmission of neural impulses in the intraneural parasympathetic ganglia and inhibiting cholinergic transmission in the synapses [10]. In addition, $\mathrm{HnBB}$ is commonly used for analgesic purposes in acute ureteral colic, the pain of labor, pregnancy termination, abdominal pain, and spasms of the gallbladder and other organs that contain smooth-muscle fibers [10-14]. The objective of this study was to investigate the analgesic effect of $\mathrm{HnBB}$ pretreatment during propofol injection in a peripheral vein.

\section{Subjects and Methods}

Sixty patients aged 18-65 years, with American Society of Anesthesiologists (ASA) physical status I and II, scheduled to undergo routine outpatient surgery under general anesthesia, were enrolled in this prospective, randomized, double-blind, and placebocontrolled study. Exclusion criteria were an allergy to the study drugs, end-stage renal disease, pregnancy, taking sedatives or analgesics, requiring a rapid sequence induction and intubation, and neurological or cardiovascular disease. The institutional ethics committee approved this study and written informed consent was obtained from all the patients. The study was registered with the 
Table 1. Comparison of patients' baseline characteristics

\begin{tabular}{lccc}
\hline & $\begin{array}{l}\text { Group H } \\
(n=30)\end{array}$ & $\begin{array}{l}\text { Group C } \\
(n=30)\end{array}$ & $p$ \\
\hline Age, years & $50.47 \pm 14.56$ & $45.07 \pm 15.12$ & 0.164 \\
Gender, M/F & $16 / 14(53 / 47)$ & $21 / 9(70 / 30)$ & 0.194 \\
Height, cm & $166.27 \pm 4.50$ & $166.67 \pm 6.80$ & 0.791 \\
Weight, kg & $74.76 \pm 10$ & $71.70 \pm 10.37$ & 0.249 \\
BMI & $27.01 \pm 3.31$ & $25.81 \pm 3.47$ & 0.176 \\
ASA, I/II & $15 / 15(50 / 50)$ & $21 / 9(70 / 30)$ & 0.094 \\
Comorbidities & & & \\
$\quad$ DM, M/F & $27 / 3(90 / 10)$ & $27 / 3(90 / 10)$ & 1.000 \\
$\quad$ Tobacco use, M/F & $20 / 10(67 / 33)$ & $24 / 6(80 / 20)$ & 0.243 \\
\hline
\end{tabular}

Values are expressed as mean $\pm \mathrm{SD}$ or $n(\%)$. M, males; F, females; DM, diabetes mellitus; Group H, hyoscine N-butylbromide; Group C, controls.

Table 2. Comparison of propofol injection pain

\begin{tabular}{llll}
\hline & $\begin{array}{l}\text { HnBB group } \\
(n=30)\end{array}$ & $\begin{array}{l}\text { Controls } \\
(n=30)\end{array}$ & $p$ \\
\hline $\begin{array}{l}\text { Patients with pain } \\
\text { Pain severity }\end{array}$ & $43.3 \%$ & $73.3 \%$ & 0.018 \\
$\quad$ No pain, $n(\%)$ & $17(56.6)$ & $8(26.6)$ & 0.001 \\
Mild, $n(\%)$ & $9(30)$ & $4(13.3)$ & \\
$\quad$ Moderate, $n(\%)$ & $1(3.3)$ & $8(26.6)$ & \\
Severe, $n(\%)$ & $3(10)$ & $10(33.3)$ & \\
\hline
\end{tabular}

Australian NZ Clinical Trial Registry (ACTRN12616000142437). The Consolidated Standards of Reporting Trials (CONSORT) flow chart detailing patient recruitment is shown in Figure 1.

Using a computer-generated block, the patients were randomized into 2 groups: Group $\mathrm{H}(n=30)$ received $20 \mathrm{mg} \mathrm{HnBB}$ and Group C (controls, $n=30$ ) received $0.9 \%$ sodium chloride. The $\mathrm{HnBB}$ and placebo ( $0.9 \%$ sodium chloride) were prepared in identical syringes by an anesthesia nurse who was blinded to the study. For each patient, the study team personnel received a syringe and a data collection sheet, both labeled with the study subject No.

For all patients, a 20-gauge intravenous cannula was inserted in the radial vein at the wrist of the right hand for administering intravenous (IV) fluids and medications. Routine monitoring (with a pulse oximeter, 3-lead ECG, and noninvasive blood pressure cuff) and preoxygenation was provided in the operating room. The assigned study drug was then injected over $2-3 \mathrm{~s}$. The intravenous line containing lactated Ringer's solution was then allowed to flow freely. After $20 \mathrm{~s}$, a $50-\mathrm{mg}$ dose of propofol (1\%) at room temperature was injected over $2-3 \mathrm{~s}$, followed again by free flow of the lactated Ringer's solution. Ten seconds after the injection of propofol, each patient was asked a standard question about the level of pain they had experienced during injection of propofol: "Are you having pain at your IV site?" and the response was noted by an anesthesiologist (M.S.U. or E.A.) blinded to the study. Injec-

Hyoscine N-Butylbromide for Propofol Injection Pain tion pain severity was assessed using the following 4-point pain response scale; no pain: 0 , mild pain (reported only in response to questioning and without behavioral signs): 1, moderate pain (reported in response to questioning and accompanied by a behavioral sign, or spontaneously without questioning): 2 , and severe pain (a strong vocal response or a response accompanied by facial grimacing, arm withdrawal, or tears): 3 [4]. Two of the investigators (M.S.U. and E.A.) performed the pain response assessments on all patients. After the assessment, the induction of general anesthesia was then completed as deemed appropriate by the anesthesiologist responsible for the care of the patient.

Demographic data, i.e., age, gender, weight, height, body mass index (BMI), ASA physical status, and comorbidities, were obtained from the medical records.

The sample size was determined according to a previous study in which pain was estimated to be $65 \%$ after $1 \%$ (50 $\mathrm{mg}$ ) IV propofol injection [3]. To reduce the pain by half with a significance level of $\alpha=0.05$ and $\beta=0.80,28$ patients were found to be sufficient for each group. However, 30 patients were included in each group due to the possibility of dropouts.

\section{Statistical Analysis}

Statistical analysis was performed using SPSS v15.0 software (SPSS Institute, Chicago, IL, USA). Parametric data were tested with the Student $t$ test and presented as means and standard deviation. Categorical data were analyzed with the Pearson $\chi^{2}$ test, and are given as numbers and proportions. A $p$ value $<0.05$ was considered statistically significant.

\section{Results}

Demographic data are summarized in Table 1. There were no significant differences between the 2 groups regarding age, gender, weight, height, BMI, ASA physical status, and comorbidities $(p>0.05)$.

The occurrence and severity of pain (as determined the pain scale) immediately after propofol injection in all groups are shown in Table 2. The occurrence of pain in group $\mathrm{H}(43.3 \%)$ was significantly lower than in group $\mathrm{C}$ $(73.3 \%)(p<0.018)$. Ten patients in group $\mathrm{C}$ and 3 in group $\mathrm{H}$ had severe pain $(p=0.001)$.

No edema, pain, wheal, or flare response was noted at the injection site or reported by any patients during the $24 \mathrm{~h}$ after the operation.

\section{Discussion}

This study demonstrates that pretreatment with $\mathrm{HnBB}$ reduced the overall occurrence and severity of pain immediately after propofol injection compared to placebo.

Although the cause of the pain during the injection of propofol is not clear, 2 basic mechanisms have been sug- 
gested. The first involves the direct irritation of the skin, mucous membranes, and venous intima, dependent on the phenol groups in the propofol [15]. The second is the indirect effect of propofol on the endothelium, whereby the kinin-kallikrein system is activated and results in the formation of bradykinin. Bradykinin increases propofol contact with the nerve endings of the vein, and consequently increases the pain associated with the propofol injection $[16,17]$. Based on the findings of this study, the mechanism is likely that suggested by Toma et al. [15].

In this study, administering $20 \mathrm{mg} \mathrm{HnBB}$ before propofol injection reduced the pain by $30 \%$ (i.e., from 73 to $43 \%)$ compared to placebo. $\mathrm{HnBB}$, an anticholinergic agent, is used for abdominal pain and spasms in organs contain smooth-muscle fibers. It binds to muscarinic receptors, blocking them (thanks to its nitrogen atom), and thereby rendering them inaccessible to ACh [18]. $\mathrm{HnBB}$ is also used as an analgesic in cases such as acute ureteral and renal colic, abdominal cramping and pain, dysmenorrhea, pregnancy termination, and after laparoscopic sterilization [10, 14, 19-23].

The pain from the propofol injection was reduced by $30 \%$ due to the $20-\mathrm{mg} \mathrm{HnBB}$ pretreatment, similar to the $37 \%$ reduction with lidocaine pretreatment [24] and the $33 \%$ reduction with low-dose esmolol [25]. However, a combination of lidocaine and nitroglycerine pretreatment has been found to reduce propofol injection pain to $7 \%$, which is better than using either lidocaine or $\mathrm{HnBB}$ alone.

In this study, the $73 \%$ incidence of propofol injection pain was higher than the $60 \%$ in the control group of another study in which the selective serotonin receptor
(5HT3) antagonist granisetron was used to alleviate pain [26]. However, this $73 \%$ was reduced by $30 \%$ due to $\mathrm{HnBB}$ pretreatment, which is a greater reduction than the $15 \%$ experienced using granisetron. Ondansetron, another 5HT3 antagonist, has also been shown to significantly reduce propofol injection pain compared to placebo [14]. Another 5HT3 antagonist, ramosetron, alleviated propofol injection pain by $30 \%$ [27]; this is similar to our findings.

The $73 \%$ pain incidence in this study was lower than the $90 \%$ in the $0.9 \%$ sodium chloride group of another study that evaluated the effect of lidocaine and methylene blue on propofol injection pain [28]. In that study, propofol injection pain was detected in $40 \%$ of the methylene blue group. Similarly, in our study, propofol injection pain was $43.3 \%$ in the $\mathrm{HnBB}$ pretreatment group.

The limitations of this study include not asking the patients to score the level of the pain by themselves and not using lidocaine alone as a positive control.

\section{Conclusion}

We found that $\mathrm{HnBB}$ administration reduced propofol injection pain. HnBB could therefore be used to alleviate propofol injection pain.

\section{Acknowledgment}

All the authors would like to thank Emre Ebem, the anesthetic nurse, for her technical support.

\section{References}

1 Picard P, Tramer MR: Prevention of pain on injection with propofol: a quantitative systematic review. Anesth Analg 2000;90:963969.

-2 Tan CH, Onsiong MK: Pain on injection of propofol. Anaesthesia 1999;53:468-767.

$\checkmark 3$ Jalota L, Kalira V, George E, et al: Prevention of pain on injection of propofol: systematic review and meta-analysis. BMJ 2011;342: d1110.

-4 Memiş D, Turan A, Karamanlioğlu B, et al: The use of magnesium sulfate to prevent pain on injection of propofol. Anesth Analg 2002; 95:606-608.

$\checkmark 5$ Dubey PK, Prasad SS: Pain on injection of propofol: the effect of granisetron pretreatment. Clin J Pain 2003;19:121-124.
6 Nathanson MH, Gajraj NM, Russell JA: Prevention of pain on injection of propofol: a comparison of lidocaine with alfentanil. Anesth Analg 1996;82:469-471.

7 King SY, Davis FM, Wels JE, et al: Lidocaine for the prevention of pain due to injection of propofol. Anesth Analg 1992;74:246-249.

$>8$ O'Hara JR Jr, Sprung J, Laseter JT, et al: Effects of topical nitroglycerin and intravenous lidocaine on propofol-induced pain on injection. Anesth Analg 1997;84:865-869.

$>9$ Kwak KH, Ha J, Kim Y, et al: Efficacy of combination intravenous lidocaine and dexamethasone on propofol injection pain: a randomized, double-blind, prospective study in adult Korean surgical patients. Clin Ther 2008;30:1113-1119.
10 Fujii Y, Nakayama M: Reduction of propofolinduced pain through pretreatment with lidocaine and/or flurbiprofen. Clin Drug Invest 2004;24:749-753.

11 Tytgat GN: Hyoscine butylbromide: a review of its use in the treatment of abdominal cramping and pain. Drugs 2007;67:13431357.

12 Papadopoulos G, Bourdoumis A, Kachrilas S, et al: Hyoscine N-butylbromide (Buscopan ${ }^{\circledR}$ ) in the treatment of acute ureteral colic: what is the evidence? Urol Int 2014;92:253-257.

13 Samuels LA, Christie L, Roberts-Gittens B, et al: The effect of hyoscine butylbromide on the first stage of labour in term pregnancies. BJOG 2007;114:1542-1546. 
14 Sirohiwal D, Dahiya K, De M: Efficacy of hyoscine-N-butyl bromide (Buscopan) suppositories as a cervical spasmolytic agent in labour. Aust NZ J Obstet Gynaecol 2005;45: 128-129.

15 Toma VA, Filip A, Farcas A, et al: Effect of hyoscine N-butylbromide on the skeletal muscle contraction in Wistar rat. Ann RSCB 2013;18:123-128.

16 Velipasaoglu M, Ayaz R, Senturk M, et al: Analgesic effects of acetaminophen, diclofenac and hyoscine N-butylbromide in second trimester pregnancy termination: a prospective randomized study. J Matern Fetal Neonatal Med 2016;29:3838-3842.

-17 Ambesh SP, Dubey PK, Sinha PK: Ondansetron pretreatment to alleviate pain on propofol injection: a randomized, controlled, double-blinded study. Anesth Analg 1999;89: 197-199.

18 Nakane M, Iwama H: A potential mechanism of propofol induced pain on injection based on studies using nafamostat mesilate. Br J Anaesth 1999;83:397-404.
19 Garaj NM, Nathanson MH: Preventing pain during injection of propofol optimal dose of lidocaine. J Clin Anesth 1996;8:575-577.

20 Evangelista S: Quaternary ammonium derivatives as spasmolytics for irritable bowel syndrome. Curr Pharm Des 2004;10:3561-3568.

21 Hernández Bueno JA, de la Jara Díaz J, Sedeño Cruz F, et al: Analgesic-antispasmodic effect and safety of lysine clonixinate and Lhyoscinbutylbromide in the treatment of dysmenorrhea. Ginecol Obstet Mex 1998;66: 35-39.

22 Mueller-Lissner S, Tytgat GN, Paulo LG, et al: Placebo- and paracetamol-controlled study on the efficacy and tolerability of hyoscine butylbromide in the treatment of patients with recurrent crampy abdominal pain. Aliment Pharmacol Ther 2006;23:1741-1748.

23 Leppert W, Okulicz-Kozaryn I, Kaminska E, et al: Analgesic effects of morphine in combination with adjuvant drugs in rats. Pharmacology 2014;94:207-213.
24 Galgon RE, Strube P, Heier J, et al: Magnesium sulfate with lidocaine for preventing propofol injection pain: a randomized, double-blind, placebo-controlled trial. J Anesth 2015;29:206-211

25 Akgün Salman E, Titiz L, Akpek E, et al: Pretreatment with a very low dose of intravenous esmolol reduces propofol injection pain. Agri 2013;25:13-18.

26 Ahmed A, Sengupta S, Das T, et al: Pre-treatment with intravenous granisetron to alleviate pain on propofol injection: a doubleblind, randomized, controlled trial. Indian J Anaesth 2012;56:135-138.

27 Singh D, Jagannath S, Priye S, et al: Prevention of propofol injection pain: comparison between lidocaine and ramosetron. J Anaesthesiol Clin Pharmacol 2014;30:213-216.

28 Salman AE, Salman MA, Saricaoglu F, et al: Pain on injection of propofol: a comparison of methylene blue and lidocaine. J Clin Anesth 2011;23:270-274. 